\title{
Developmental Strategies in Diagnosing Obstructive Sleep Apnea
}

\author{
V. Santhiya, T. Ravichandran, G. Yamuna, K. Harini
}

\begin{abstract}
A key mission in medical science is diagnosing a disease due to its criticality and accuracy in examining whether a patient is suffering from particular disease or not. Then, the most appropriate side of treatment can be decided. Obstructive Sleep Apnea (OSA) syndrome is the most widespread sleep disorder characterized by chronic episodes of reduction in the airflow or stoppage in airflow during sleep, being caused by blockage of upper airway. The intention of this review is to analyze already existing algorithms for detecting apnea all the way through usage of different sensors that have not been implemented on hardware. This study offers an exhaustive literature research value from 2003 to 2019 and setting a roadmap for bio-engineers and medical doctors thereby reducing research period and improving medical service efficiency concerning obstructive sleep apnea diagnosis.
\end{abstract}

Keywords: Algorithms review, diagnosis approaches, obstructive sleep apnea, Sleep disorder.

\section{INTRODUCTION}

In medical science, diagnosing a particular disease in precedence of its treatment is the major difficulty find. Hence diagnosis plays a significant role to examine whether or not a patient has a possible disease. The present work focuses on OSA diagnosis methods.

Sleep disorders are familiar health condition that affects various aspects of life. International Classification of Sleep Disorder have recognized more than 60 different types of sleep disorders and categorized them into seven groups. Obstructive sleep apnea belongs to second category and is characterised by frequent events of reduction or complete blockage of breathing during sleep and is due to collapse of upper airway. Apnea is the full obstruction of airway and hypopnea is the partial obstruction of airway when a person is asleep and breathing may be inadequate for 10 seconds or even longer. This lowers the level of oxygen in blood and in central nervous system. Brain senses this impaired breathing and arouses individuals from sleep so that the airway can be reopened. This awakening is so brief and breathing typically resumes with some gasping sounds and body jerk. A noticeable sign of this disorder is severe snoring and poor sleep quality.

Revised Manuscript Received on February 18, 2020.

* Correspondence Author

V. Santhiya*, Student of Annamalai University, Chidambaram.

Mr. T. Ravichandran, Associate Professor, Department, Electronics and Communication Engineering, Annamalai University. Chidambaram.

Dr. G. Yamuna, Professor and Head, Department, Electronics and Communication Engineering, Annamalai University. Chidambaram.

K. Harini, Student of Annamalai University, Chidambaram.

(C) The Authors. Published by Blue Eyes Intelligence Engineering and Sciences Publication (BEIESP). This is an open access article under the CC BY-NC-ND license (http://creativecommons.org/licenses/by-nc-nd/4.0/)
OSA individuals of about $25 \%$ reports excessive daytime sleepiness. Patients of greater proportion report unrefreshing sleep or fatigue [1]. Other important symptoms may include recurrent nocturnal waking due to gasping or choking sounds, nocturia, long existing morning headaches, and erectile dysfunction and poor concentration [2-4]. OSA affect people of all ages including childrens and its prevalence increases for aged people (50 years and above). Around 1 in 5 adult individual notices mild symptoms, while 1 in 15 individuals have moderate to severe symptoms of OSA. Obesity is a main risk factor and is seen in upto $70 \%$ of obese individuals.

American Academy of Sleep Medicine (AASM) has projected four levels of categorization for the sleep related disorder diagnostic devices [5]. Polysomnography (PSG level I study) is the gold model technique for diagnosing obstructive sleep apnea. It involves monitoring of seven or even more channels of data to record activity of different organ systems associated with sleep such as breathing airflow signal, respiratory movement, oxygen saturation (SpO2), Electrooculogram (EOG), electroencephalogram (EEG), electromyogram (EMG), electrocardiogram (ECG) signals and position of body[6]. OSA syndrome is detected if individual with indicated symptoms shows five or even more events of respiration per hour of sleep during night study of PSG [7]. Risk phase of apnea can be defined as normal ( $0-5$ events/hour), $5 \leq \mathrm{AHI}<15$ events/hour is reported as mid, $15 \leq \mathrm{AHI}<30$ events/hour is reported as moderate and above 30 events/hour is reported as severe. Home based polysomnography (level II study) is used only for research purposes. Level III study involves recording minimum of 3 channels of data such as airflow, snoring, body posture, heart rate, respiratory excursion and oxygen saturation level but does not records sleep. Hence respiratory event index is used to estimate severity of OSA. Level IV study involves recording of less than or two channels of data. Oximetry is one channel while the other records heart rate, airflow or snoring.

PSG provides precise results but it is an expensive and very slow process. It usually requires the patient to be in the sleep laboratory under the supervision of expert technicians. Using portable PSG devices, the test can be carried out in patient's home but use of all necessary sensors makes uncomfortable experience. To address this issue, alternate devices (level IV study) have been developed to observe patients with fewer sensors and different diagnosis algorithms [8]. 


\section{Developmental Strategies in Diagnosing Obstructive Sleep Apnea}

\section{METHODS AND ALGORITHMS}

In this section considerable amount of work has done to reassess papers that have offered algorithms based on analyses of respiration, ECG and pulse oximetry since these seems to be more potential approaches to detect OSA.

\section{A. Based On Oximetry}

Pulse oximetry is a method to measure the amount of haemoglobin (in percentage) saturated with oxygen. Among large number of polysomnographic recordings, [9] included recordings for individuals with age of $\geq 18$ years and excluded individuals with parasomnia, chest wall diseases, lung diseases, anaemia and ischemic heart disease. Apnea Hypopnea Index with 0 to 86.5 events per hour from 230 polysomonographic recordings which met above criteria are categorized into 138 training sets and 92 test sets. Apneic event occurrence is denoted by three points A,B and C.
Point $\mathrm{A}$ indicates the decrease in value of $1 \% \leq \mathrm{SpO} 2 \leq 3 \%$. Point $\mathrm{B}$ indicates decrease in $\mathrm{SpO} 2$ signal to atleast $3 \%$ below point $\mathrm{A}$. If $\mathrm{SpO} 2$ value returns to either $3 \%$ above point $\mathrm{B}$ or $1 \%$ below point $\mathrm{A}$, it is marked as point $\mathrm{C}$. The total time taken between point $\mathrm{A}$ and $\mathrm{C}$ should be $\geq$ 10 seconds and $\leq 90$ seconds. From detection results AHI index are estimated using regression modelling.

[10] used two nonlinear characteristics such as and Lempel-Ziv complexity and Cumulative Tendency Measure methods to detect OSA. Three stage algorithm was used by [11] such as feature extraction, pre-processing with principal component analysis and statistical classifier.

The photoplethysmogram signal is monitored for decrease in amplitude fluctuations. With the features of Pulse Rate

Table-I: Comparitive Study Of Analyzed Algorithms

\begin{tabular}{|c|c|c|c|c|c|}
\hline $\begin{array}{l}\text { Source } \\
\text { sensor }\end{array}$ & $\begin{array}{l}\text { Year in } \\
\text { which } \\
\text { proposed }\end{array}$ & $\begin{array}{l}\text { Technique or } \\
\text { Methodology }\end{array}$ & Accuracy\% & Advantages & Limitation \\
\hline \multirow{7}{*}{ ? } & 2018 & Regression modelling & $96.7 \%$ & $\begin{array}{l}\text { Not only provides diagnostic } \\
\text { information but also timing } \\
\text { information of apneic events. }\end{array}$ & $\begin{array}{l}\text { Difficult to categorise whether the } \\
\text { detected apneic event is central } \\
\text { apnea, obstructive apnea or mixed } \\
\text { sleep apnea. }\end{array}$ \\
\hline & 2006 & $\begin{array}{l}\text { Lempel-Ziv complexity and } \\
\text { Central Tendency Measure }\end{array}$ & $87.2 \%$ & Improved sensitivity and specificity. & Small sample size. \\
\hline & 2010 & $\begin{array}{c}\text { Principal Component } \\
\text { Analysis(PCA) and Linear } \\
\text { Discriminant Analysis } \\
\text { (LDA) }\end{array}$ & $93.02 \%$ & $\begin{array}{l}\text { Improved Classification performance } \\
\text { due to the combination of nonlinear } \\
\text { and spectral features from oximetry } \\
\text { data. }\end{array}$ & $\begin{array}{l}\text { Doubtful subjects are labelled as } \\
\text { OSA Syndrome positive. }\end{array}$ \\
\hline & 2013 & $\begin{array}{l}\text { Pulse Rate Variability } \\
\text { (PRV) }\end{array}$ & $86.67 \%$ & $\begin{array}{l}\text { PRV discriminate apneic events } \\
\text { without need of additional signals. }\end{array}$ & $\begin{array}{l}\text { 1. Accuracy for fragment } \\
\text { classification computed using } \\
\text { leave-one-out method produced } \\
\text { only smaller accuracies. } \\
\text { 2. Limited subjects in database } \\
\end{array}$ \\
\hline & 2014 & $\begin{array}{c}\text { Time varying } \\
\text { characterization of PRV } \\
\text { and } \mathrm{SpO} 2\end{array}$ & $92.6 \%$ & Portable and less sleep disturbance. & $\begin{array}{l}\text { Recordings are done only at } \\
\text { hospital. Not suitable for home } \\
\text { screening due to severe sensor } \\
\text { displacement. }\end{array}$ \\
\hline & 2017 & $\begin{array}{c}\text { Artificial Neural Network } \\
\text { classifier and Genetic } \\
\text { Algorithm } \\
\end{array}$ & $97.7 \%$ & $\begin{array}{l}\text { Identified that most of apneic event } \\
\text { information are in time-frequency } \\
\text { space and improved accuracy. }\end{array}$ & $\begin{array}{l}\text { Multilayer Perceptron (MLP) } \\
\text { structure is calculated using thumb } \\
\text { rule and is subject dependent. }\end{array}$ \\
\hline & 2017 & Deep Belief Network & $\begin{array}{c}\text { UCDDB- } \\
85.26 \% \\
\text { Apnea ECG } \\
\text { database- } \\
97.64 \% \\
\end{array}$ & $\begin{array}{l}\text { Outperformed than other feature based } \\
\text { approaches in both databases. }\end{array}$ & $\begin{array}{l}\text { Unbalanced data due to prevalence } \\
\text { of non apnea events and fixed } \\
\text { Deep Belief Network structure. }\end{array}$ \\
\hline \multirow{2}{*}{ :0 } & 2013 & $\begin{array}{l}\text { k- Nearest Neighbour } \\
(\mathrm{kNN})\end{array}$ & $91.2 \%$ & $\begin{array}{l}\text { Accurately detects apneic events from } \\
\text { respiratory impedance signal. }\end{array}$ & $\begin{array}{c}\text { Small sample set. Accuracy can be } \\
\text { achieved higher if used with ECG } \\
\text { analysis. Value of k has a greater } \\
\text { impact on accuracy. }\end{array}$ \\
\hline & 2015 & $\begin{array}{c}\text { Ensemble classifiers- } \\
\text { AdaBoost, Random } \\
\text { subspace \& Random Forest }\end{array}$ & $98.68 \%$ & $\begin{array}{l}\text { All three classifiers achieved good } \\
\text { accuracy due to its robustness and } \\
\text { stability. Amongst all, random forest } \\
\text { achieved high accuracy of } 98.68 \% \text {. }\end{array}$ & - \\
\hline
\end{tabular}




\begin{tabular}{|c|c|c|c|c|c|}
\hline $\begin{array}{l}\text { Source } \\
\text { sensor }\end{array}$ & $\begin{array}{c}\text { Year in } \\
\text { which } \\
\text { proposed }\end{array}$ & $\begin{array}{l}\text { Technique or } \\
\text { Methodology }\end{array}$ & Accuracy & Advantages & Limitation \\
\hline & 2012 & $\begin{array}{l}\text { Support Vector Machine } \\
\text { (SVM) }\end{array}$ & $\begin{array}{c}\text { Independent test } \\
\text { accuracy and } \\
\text { Cross-validation } \\
\text { accuracy -For } \\
\text { apnea event } \\
\text { 92.8\% \& 93.3\%. } \\
\text { For hypopnea event } \\
\text { 89.6\% \& 90.1\%. }\end{array}$ & $\begin{array}{l}\text { Apneic event detection is not } \\
\text { affected by less than two } \\
\text { misclassifications. }\end{array}$ & $\begin{array}{c}\text { Detection accuracy of hypopnea event } \\
\text { is poor. Also, error occurs in seperating } \\
\text { hypopnea from combined event } \\
\text { (apnea+hypopnea). }\end{array}$ \\
\hline & 2013 & $\begin{array}{l}\text { Adaptive two stage } \\
\text { classifier }\end{array}$ & $\begin{array}{c}\text { Apnea- } 94.9 \% \\
\text { Hypopnea- } 91.8 \% \\
\text { Combined event- } \\
\text { 96.5\% }\end{array}$ & $\begin{array}{l}\text { Automatically estimates AHI } \\
\text { and can be implemented in } \\
\text { type4 personal monitoring } \\
\text { devices as per AASM } \\
\text { guidelines. }\end{array}$ & $\begin{array}{l}\text { Clinical validation study carried out on } \\
\text { small datasets. Requires adjustment for } \\
\text { different datasets hence unstable. } \\
\text { Thermistor response to detect apnea } \\
\text { events is poor }\end{array}$ \\
\hline & 2016 & $\begin{array}{l}\text { AdaBoost and } \\
\text { ANFIS }\end{array}$ & $\begin{array}{c}\text { AdaBoost- } 98.43 \% \\
\text { ANFIS-98.68\% }\end{array}$ & High detection reliability & Small dataset \\
\hline \multirow{3}{*}{ 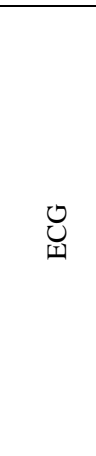 } & 2017 & $\begin{array}{l}\text { Dual-tree complex } \\
\text { wavelet transform and } \\
\text { Logistic Boosting } \\
\text { classifier }\end{array}$ & $84.4 \%$ & $\begin{array}{l}\text { High sensitivity (less missing } \\
\text { detections). Doesn't involve } \\
\text { denoising, preprocessing or } \\
\text { rejections of artifacts. }\end{array}$ & - \\
\hline & 2016 & $\begin{array}{c}\text { Normal Inverse } \\
\text { Gaussian (NIG) } \\
\text { modelling, } \\
\text { Tunable Q-factor } \\
\text { Wavelet Transform } \\
\text { (TQWT) and Adaptive } \\
\text { boosting (AdaBoost). } \\
\end{array}$ & $87.33 \%$ & $\begin{array}{l}\text { TQWT adjusts Q factor lower } \\
\text { and higher to characterize non- } \\
\text { apneic and apneic segments. } \\
\text { Hence provides satisfactory } \\
\text { performance. }\end{array}$ & $\begin{array}{l}\text { Does not support larger data set. Apart } \\
\text { from OSA, ECG signals are affected } \\
\text { by many cardiac conditions. Data set } \\
\text { used for validation purpose includes } \\
\text { only healthy or apneic subjects. }\end{array}$ \\
\hline & 2016 & $\begin{array}{l}\text { TQWT and Random } \\
\text { Under Sampling } \\
\text { Boosting (RUSBoost) }\end{array}$ & $\begin{array}{l}\text { UCDDB-91.94\% } \\
\text { Apnea ecg dataset- } \\
\text { 88.88\% }\end{array}$ & $\begin{array}{l}\text { Computationally inexpensive. } \\
\text { Does not experience mode } \\
\text { mixing problems. }\end{array}$ & - \\
\hline
\end{tabular}

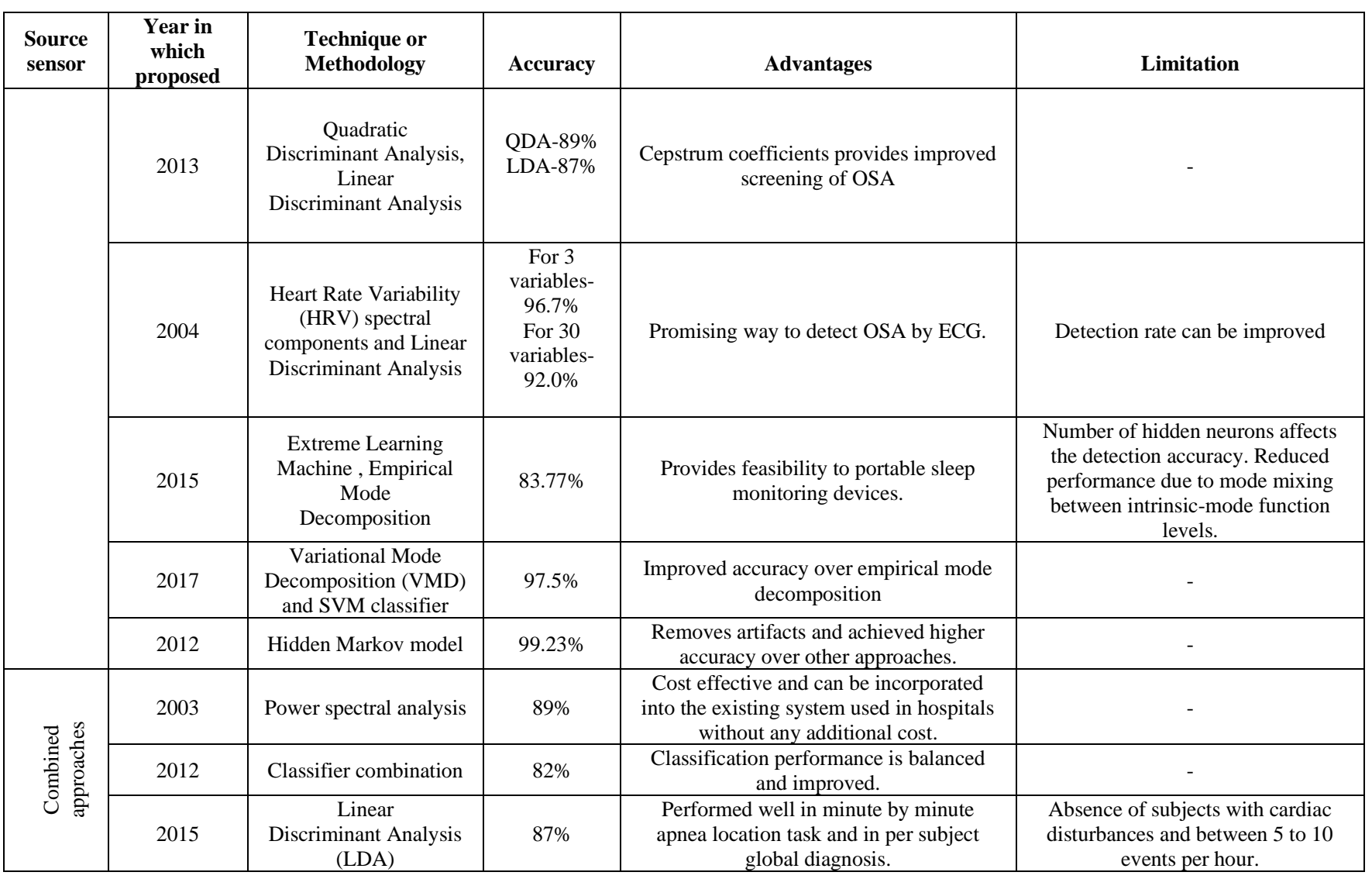

Published By:

Blue Eyes Intelligence Engineering 


\section{Developmental Strategies in Diagnosing Obstructive Sleep Apnea}

\begin{tabular}{|c|c|c|c|c|c|}
\hline 2009 & Logistic regression & $88.5 \%$ & $\begin{array}{c}\text { Median frequency and spectral entropy } \\
\text { provides rich information in OSA } \\
\text { diagnosis when used SaO2 with EEG } \\
\text { signal. }\end{array}$ & $\begin{array}{c}\text { Study data could be larger since } \\
\text { individuals with OSA positive were } \\
\text { predominant. }\end{array}$ \\
\cline { 2 - 5 } & 2017 & $\begin{array}{c}\text { Multi-modal approach } \\
\text { and Support Vector } \\
\text { Machine }\end{array}$ & $96.64 \%$ & $\begin{array}{c}\text { Multi-modal technique performed for } \\
\text { SpOnd ECG signals with feature level } \\
\text { fusion achieved highest accuracy of } \\
\text { classification with SVM than all other } \\
\text { scenarios. }\end{array}$ & $\begin{array}{c}\text { Accuracy decreased when SVM } \\
\text { used with single modal approach. }\end{array}$ \\
\hline
\end{tabular}

UCDDB- University College of Dublin sleep apnea DataBase

Variability, Linear Discriminant Analysis classifies the data in [12]. [13] measured number of desaturation events per hour, , length of trace and the time with oxygen saturation less than $90 \%$ and then classified apnea events based on physiology. Combination of time and frequency domain characteristics obtained from PRV and SpO2 signals were used by [13]. Artificial Neural Network were employed by [14] to identify features of blood oxygen saturation and achieved 97.7\% accuracy.[15] uses 3 layer learning model - first two layers for Boltzmann machine and third is a soft max layer.

\section{B. Based On Respiration}

A novel approach was proposed by [16] in which a coil of wire was first strapped around the rib cage of an individual. Then, respiratory signal is obtained by measuring the impedance of a coil. Peak to peak time, Peak height stability value, flat lining and long pauses occurrence were extracted and applied to kNN. [17] employed time frequency method by applying Hilbert Huang transform to nasal airflow signal. The airflow signal is decomposed into minimum, maximum and average by wavelets and skewness, entropy and energy were obtained by [18] and used three classifiers such as AdaBoost, Random forest and Random subspace. To detect OSA, [19] used oronasal airflow signal. The signal was filtered at first by butterworth filter and then segmented into features. With the three extracted features, apneic datas are classified by Support Vector Machine classifier. [20] Used airflow signal with same filter and performed two steps. First, to detect sleep disorder and the other is to classify either as apnea or hypopnea. [21] Extracted the statistical features of airflow signal by decomposing it by Daubechies wavelet. Classifiers such as Adaptive Neuro Fuzzy Inference System and AdaBoost are used to classify the data amongst which the best performance is achieved by ANFIS. [22] Utilized characteristic moment waveform to detect respiratory rate by segmenting the sound of breathing signal during sleep.

\section{Based On ECG}

Electrocardiogram waveforms are analyzed to detect sleep disorders. ECG signals are segmented in [23] and frequency sub bands are generated from dual tree wavelet transform. Logistic boosting classifier is used to detect apnea situations. [24] Followed same method but used tunable Q factor wavelet transform and adaptive boosting classifier. [25] Divided the ECG signals into segments each of 1 minute duration and extracted spectral and statistical features from each segments. Random under sampling boosting is used as classification model to classify apnea events. Cepstrum features from RR series are fed into LDA and QDA classifiers in [26]. Frequency information such as low, high, ultra-low and very-low frequency, high were used by [27] to classify using LDA. Different decomposition methods such as Empirical- Mode Decomposition (EMD) [28] and Variational-Mode Decomposition (VMD) [29] are utilized to decompose electrocardiogram signals into variational mode functions and finite intrinsic mode functions. [30] Presented a different approach using multi source information of ECG signal in combination with index based cross correlation. Breathing results in modulation in the amplitude of $\mathrm{T}$ and $\mathrm{R}$ waves. [31] analyzed that sleep disorders can be predicted using Morphology of ECG and heart rate by cardio-pulmonary coupling. Multi resolution wavelet transforms are used by [32] to separate ECG into alpha, beta, delta and theta spectral components and these coefficients were fed as input into neural networks. [33] Presented a detection algorithm that divides the spectral power in VLF band of RR series and calculates power ratio based coefficients. SVM and Gaussian mixture model classifiers are tested and best results were obtained using SVM. Signals such as RR and EDR (ECG derived respiration) are decomposed by [34] using 14-levels of Daubechies wavelet and fed into SVM to classify OSA events. [35] Used coefficients of RR series with SVM classifier and Hidden Markov Model. [36] Used three stages to classify apnea data. First stage, ECG data are analysed for changes in EDR and HRV. In second stage, power spectral density was used to obtain features from EDR and HRV. Then, Hill climbing algorithm is used to select best features. In third stage, SVM classifier is used to classify apnea and normal data.

\section{Based On Combined Approaches}

OSA can be detected by considering only $\mathrm{SpO} 2$ signals but [37] used both heart rate and $\mathrm{SpO} 2$ signals from pulse oximeter. Peaks in the frequency band of both signals are used to classify apnea events. A different approach was presented by [38] where a combination of ECG and SpO2 signals was used. The features derived from these signals are analysed using correlation based subset selection and fed into three different classifiers. Combination of SpO2 and RR series are employed by [39] in which features in both frequency and time domain were extracted from RR series. Then LDA classifier was used to classify segments either apnea or normal. [40] Performed fusion at feature level of two signals such as SpO2 and ECG by employing multimodal techniques. The resultant signals are tested by kNN, SVM and Naive Bayes classifiers. PPG and nasal airflow signals were used by [41] to detect arousals and presented apnea hypopnea index and respiratory disturbance index.[42]Developed a sleepcare kit with photoplethysmography (PPG),

nasal tube of PPG equipment to measure breathing signals and IMU sensor to determine posture. The measured datas are analyzed to detect apnea or hypopnea in real time. 


\section{RESULTS AND DISCUSSION}

Thus a wide survey on previous works has been carried out covering different approaches in detecting OSA. Summary of papers presented and corresponding algorithms used is shown in table I. The table is categorised into four sections, related to different approaches analysed. By analysing algorithms, the highest accuracy was reported by [14] based on oximetry, [18] and [21] using respiration analysis, [35] based on ECG and [40] with combined approaches. Maximum sensitivity was reported by [12] and [14] using oximetry analysis and by [29] using analysis of ECG signals. [36] Used ECG signals and achieved 100\% results for best classification, specificity and sensitivity. It is observed that based on single sensor approach, OSA is detected with highest accuracy by ECG signals since these electrocardiogram signals achieved best classification results. Most algorithms using electrocardiogram signals were tested on clear signals obtained from public databases. This could add a way to improve diagnosis. Combined approaches did not add to relevant advancement of classification capability. Algorithms with single source sensor to detect OSA are preferred due to their reduced complexity for hardware implementation. Classifiers such as kNN, SVM and NN were used in majority of works. Some work achieved good performance with high complexity. The key aspect is to obtain a method with good performance and reduced complexity.

\section{CONCLUSION}

This review provides an overall analysis of existing algorithms to produce a robust tool for diagnosis of OSA. This can be a future direction for researchers to implement the analyzed algorithms in hardware and more research on self learning the classified features. The key aspect is to obtain a method with good performance and reduced complexity. With this intent, a special interest is to develop a home diagnosing device with reduced numeral of sensors and reduction in cost of diagnosis. Adapting proposed algorithms in efficient hardware and self learning the features is the key challenge identified. This work is essential, since it help patients by creating awareness and perhaps prevention too among peoples.

\section{REFERENCES}

1. R.Tkacova, Z. Dorkova, "Clinical presentations of OSA in adults," Eur Respir Monogr, vol,pp.86-103,2010.

2. S.V. Kellesarian, V.R. Malignaggi, C. Feng and F. Javed, "Association between obstructive sleep apnea and erectile dysfunction: a systematic review and meta-analysis", International Journal of Impotence Research, vol.30, pp.129-140, 2018.

3. S.Musman, V.M.D.A. Passos, I.B.R Silva, S.M. Barreto, "Evaluation of a prediction model for sleep apnea in patients submitted to polysomnography”,Jornal Brasileiro de Pneumologia, vol. 37, no.1, 2011.

4. A. Qaseem, J.E. Holty, D.K. Owens, P. Dallas , M. Starkey ,P. Shekelle, "Management of obstructive sleep apnea in adults: A clinical practice guideline from the American College of Physicians", Clinical Guidelines Committee of the American College of Physicians ,An Intern Med. vol.159, no.7, pp. 471,2013.

5. Nancy A. Collop, W. McDowell Anderson, Brian Boehlecke,David Claman, Rochelle Goldberg, Daniel J. Gottlieb, David Hudgel, Michael Sateia,Richard Schwab, "Clinical Guidelines for the Use of Unattended Portable Monitors in the Diagnosis of Obstructive Sleep
Apnea in Adult Patients", JCSM Journal of clinical sleep medicine, vol. 3, no. 7, 2007.

6. L. Almazaydeh, K. Elleithy and M. Faezipour, "Detection of Obstructive Sleep Apnea Through ECG Signal Features," in 2012 IEEE International Conference on Electro Information Technology, Indiana, USA, May 2012.

7. Michael J. Thorpy, "Classification of Sleep Disorders" ,The American Society for Experimental NeuroTherapeutics, vol.9, no.4, pp. $687-$ $701,2012$.

8. Meir H. Kryger, Thomas Roth, William C. Dement, "Principle and Practise of Sleep Medicine", $6^{\text {th }}$ edition, 2017.

9. D. Jung, S. Hwang, J. Cho, B. Choi, H. Baek, Y. Lee, D.-U. Jeong and K. Park, "Real-Time Automatic Apneic Event Detection Using Nocturnal Pulse Oximetry," IEEE Transactions on Biomedical Engineering, 2018.

10. Schmittendorf, B. Schultheiß , M. Goffart and N. Böhning "Obstructive Sleep Apnea Screening using Nonlinear Characteristics of Overnight Pulse Oximetry Recording", IFMBE Proceedings, 25/IV, pp. 724-727, 2009.

11. D. Álvarez, L. Kheirandish-Gozal, G.C. Gutiérrez-Tobal, A. Crespo, M.F. Philby, M. Mohammadi, F. Campo, D. Gozal, and R. Hornero, "Automated Analysis of Nocturnal Oximetry as Screening Tool for Childhood Obstructive Sleep Apnea-Hypopnea Syndrome", $37^{\text {th }}$ Annual International Conference of the IEEE Engineering in Medicine and Biology Society,2015.

12. J. Lazaro, E. Gil, J. Vergara and P. Laguna, "Pulse Rate Variability Analysis for Discrimination of Sleep-Apnea-Related Decreases in the Amplitude Fluctuations of Pulse Photoplethysmographic Signal in Children," IEEE Journal of Biomedical and Health Informatics, vol. 18, no. 1, pp. 240-246, 2013.

13. R.M Burke, B. Maxwell, C. Hunter, D. Graham, D. O'Donoghue, M.D Shields "Night-to-night variation of pulse oximetry in children with sleep-disordered breathing", Arch Dis Child vol.101,pp.10951099, 2016.

14. S.S. Mostafa, J.P. Carvalho, F. Morgado- Dias, A. Ravelo-Garcia, "Optimization of Sleep Apnea Detection using SpO2 and ANN," XXVI International Conference on Information, Communication and Automation Technologies, Sarajevo, Bosnia-Herzegovina, 26-28 October 2017.

15. S. Mostafa, F. Mendonca, F. Morgado-Dias and A. Ravelo-García, "SpO2 based sleep apnea detection using deep learning," in 2017 21st International Conference on Intelligent Engineering Systems, Larnaca, Cyprus, October 2017.

16. A. Thommandram, J. Eklund and C. McGregor, "Detection of apnoea from respiratory time series data using clinically recognizable features and kNN classification," 35th Annual International Conference of the IEEE Engineering in Medicine and Biology Society, Osaka, Japan, July 2013.

17. Q. Ashton Acton, "Sleep Apnea Syndromes: Advances in Research and Treatment" 2011 edition.

18. C. Avci and A. Akbas, "Sleep apnea classification based on respiration signals by using ensemble methods," Bio-Medical Materials and Engineering, vol. 26, pp. S1703-S1710, 2015.

19. B. Koley and D. Dey, "Automated detection of apnea and hypopnea events," in 2012 Third International Conference on Emerging Applications of Information Technology, West Bengal, India, December 2012.

20. B. Koley and D. Dey, "Real-Time Adaptive Apnea and Hypopnea Event Detection Methodology for Portable Sleep Apnea Monitoring Devices," IEEE Transactions on Biomedical Engineering, vol. 60, no. 12, pp. 3354-3363, 2013.

21. P. Minu and M. Amithab, "SAHS Detection Based on ANFIS Using Single Channel Airflow Signal," International Journal of Innovative Research in Science, Engineering and Technology, vol. 5, no. 7, pp. 13053-13061, 2016.

22. [22]. Y. Fang, Z. Jiang and H. Wang "A Novel Sleep Respiratory Rate Detection Method for Obstructive Sleep Apnea Based on Characteristic Moment Waveform" Journal of Healthcare Engineering,2018.

23. [23]. A.R Hassan, S.K Basharz and M.I.H Bhuiyanx, "Computerized obstructive sleep apnea diagnosis from single-lead ECG signals using dual-tree complex wavelet transform," IEEE Region 10 Humanitarian Technology Conference, 21 - 23 Dec 2017.

24. A. Hassan, "Computer-aided obstructive sleep apnea detection using normal inverse Gaussian parameters and adaptive boosting," Biomedical Signal Processing and Control, vol. 29, no. 1, pp. 22-30, 2016. 


\section{Developmental Strategies in Diagnosing Obstructive Sleep Apnea}

25. A. Hassan and A. Haque, "Identification of Sleep Apnea from SingleLead Electrocardiogram", IEEE International Conference on Computational Science and Engineering, IEEE International Conference on Embedded and Ubiquitous Computing, and International Symposium on Distributed Computing and Applications to Buissness, Engineering and Science,2016.

26. A. Ravelo-Garcia, J. Navarro-Mesa, E. Hemadez-Perez, S. MartinGonzalez, P. Quintana-Morales, I. Guerra-Moreno and G. Julia-Serda, "Cepstrum feature selection for the classification of Sleep ApneaHypopnea Syndrome based on heart rate variability," in 2013 Computing in Cardiology Conference, Zaragoza, Spain, September 2013.

27. C. Zywietz, V. Einem, B. Widiger and G. Joseph, "ECG analysis for sleep apnea detection," Methods of Information in Medicine, vol. 43, no. 1, pp. 56-59, 2004.

28. A. Hassan, "Automatic screening of Obstructive Sleep Apnea from single-lead Electrocardiogram," in 2015 International Conference on Electrical Engineering and Information Communication Technology, Dhaka, Bangladesh, May 2015.

29. A. Smruthy and M. Suchetha, "Real-Time Classification of Healthy and Apnea Subjects Using ECG Signals With Variational Mode Decomposition," IEEE sensors journal, vol. 17, no. 10, pp. 3092 3099, May 2017.

30. C. Maier, H. Wenz and H. Dickhaus, "Robust detection of sleep apnea from Holter ECGs," Methods of Information in Medicine, vol. 53, no. 4, pp. 303-307, 2014

31. T. Penzel, J. Kantelhardt, R. Bartsch, M. Riedl, J. Kraemer, N. Wessel, C. Garcia, M. Glos, I. Fietze and C. Schobel, "Modulations of Heart Rate, ECG, and Cardio-Respiratory Coupling Observed in Polysomnography," Frontiers in Physiology, vol. 7, 2016.

32. R. Lin, R. Lee, C. Tseng, H. Zhou, C. Chao and J. Jiang, "A New Approach for Identifying Sleep Apnea Syndrome Using Wavelet Transform and Neural Networks," Biomedical Engineering Applications Basis and Communications, vol. 18, no. 3, pp. 138-143, 2006.

33. A. Ravelo-García, C. Travieso, F. Lorenzo, J. Navarro, S. Martín, J. Alonso and M. Ferrer, "Application of Support Vector Machines and Gaussian Mixture Models for the Detection of Obstructive Sleep Apnoea based on the RR Series," 8th WSEAS International Conference on Applied Mathematics, Tenerife, Spain, December 2005.

34. A. Khandoker, M. Palaniswami and C. Karmakar, "Support Vector Machines for Automated Recognition of Obstructive Sleep Apnea Syndrome From ECG Recordings," IEEE Transactions on Information Technology in Biomedicine, vol. 13, no. 1, pp. 34-48, 2009.

35. C. Travieso, J. Alonso, M. Pozo-Banos, J. Ticay-Rivas and K. Lopezde-Ipina "Automatic Apnea Identification by Transformation of the Cepstral Domain," Cognitive Computation, vol. 4, no. 4, pp. 558-565, 2012.

36. A. Yildiz, M. Akin and M.Poyraz, "An expert system for automated recognition of patients with obstructive sleep panea using electrocardiogram recordings," Expert systems with applications: An international journal, vol. 38, no. 10, pp. 12880- 12890, September 2011.

37. C. Zamarrón, F. Gude, J. Barcala, J. Rodriguez and P. Romero, "Utility of oxygen saturation and heart rate spectral analysis obtained from pulse oximetric recordings in the diagnosis of sleep apnea syndrome," Chest, vol. 123, no. 5, pp. 1567-1576, 2003.

38. B. Xie and H. Minn, "Real-Time Sleep Apnea Detection by Classifier Combination," IEEE Transactions on Information Technology in Biomedicine, vol. 16, no. 3, pp. 469-477, 2012.

39. A. Ravelo-García, J. Kraemer, J. Navarro-Mesa, E. Hernández-Pérez, J. Navarro-Esteva, G. Juliá-Serdá, T. Penzel and N. Wessel, "Oxygen Saturation and RR Intervals Feature Selection for Sleep Apnea Detection," Entropy, vol. 17, no. 5, pp. 2932-2957, 2015.

40. G. Memis and M. Sert, "Multimodal Classification of Obstructive Sleep Apnea using Feature Level Fusion," IEEE 11th International Conference on Semantic Computing, California, USA, February, 2017.

41. D. Sommermeyer, D. Zou, L. Grote and J. Hedner, "Detection of sleep disordered breathing and its central/obstructive character using nasal cannula and finger pulse oximeter," Journal of Clinical Sleep Medicine, vol. 8, no. 5, pp. 527-533, 2012.

42. Y.J. Jeon and S.J. Kang, " Analysis and prevention of Sleep Apnea Symptoms in real-time,” IEEE Access, vol. 7, pp. 60634-60649,2019.

\section{AUTHORS PROFILE}

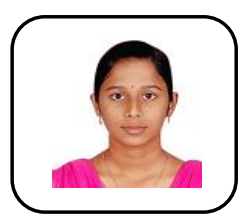

V.Santhiya, is a student of Annamalai University, Chidambaram. She completed her B.E. degree in Electronics and Communication Engineering from Jeppiaar SRR Engineering College, Chennai. She is currently pursuing post graduation in engineering (Communication Systems) at Annamalai University.

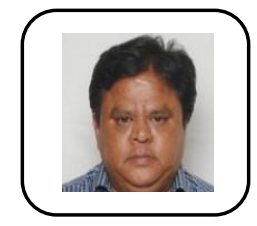

Mr.T.Ravichandran, is working as an Associate Professor in Department of Electronics and Communication Engineering, Annamalai University. He has 30years of teaching experience. He has published 5 papers and his field of specialization includes Bio signal processing and presently on RF short range communication.

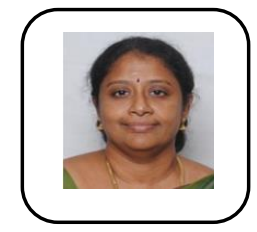

Dr.G.Yamuna, is working as a Professor and Head in Electronics and Communication Engineering, Annamalai University. She has 27 years of teaching and research experience. She has published nearly 75 papers in International journals and 38 papers in National and International conferences. Her field of specialization includes Signal processing, Video processing, Information security, Wireless communication systems and Antenna design.

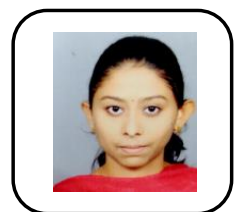

K.Harini, is a student of Annamalai University, Chidambaram. She completed her B.E. degree in Electronics and Communication Engineering and currently pursuing post graduation in engineering (Communication Systems) at Annamalai University. 